\title{
Adverse Effects of Parenteral Dexamethasone in the Treatment of Pemphigus Vulgaris.
}

\author{
Mohammad Jamal Uddin ${ }^{1}$, A.Z.M Maidul Islam², Mohammad. Eakub Ali ${ }^{3}$, Md Abdul Wahab ${ }^{3}$, Lubna Khondker ${ }^{1}$ \\ ${ }^{1}$ Assistant Professor, Department of Dermatology and Venereology, Bangabandhu Sheikh Mujib Medical University (BSMMU), Dhaka. ${ }^{2}$ Former \\ Chairman, Department of Dermatology and Venereology, BSMMU, Dhaka. ${ }^{3}$ Professor, Department of Dermatology and Venereology, Bangabandhu \\ Sheikh Mujib Medical University (BSMMU), Dhaka, Bangladesh.
}

\begin{abstract}
:
Background: Pemphigus vulgaris is associated with high morbidity as well as significant mortality rate. Today the risk of death in pemphigus from the side effect of oral prednisolone is greater than risk of death from the disease itself. Objective: To observe the adverse effects of parenteral dexamethasone compared with oral prednisolone in the treatment of pemphigus vulgaris. Methods: An interventional study was carried out in the department of Dermatology and Venereology, Bangabandu Sheikh Mujib Medical University, Dhaka, Bangladesh. Total number of patients was thirty and among them fifteen patients were treated with parenteral dexamethasone (Group-A) and other fifteen were treated with oral prednisolone (Group-B). Results: The study showed statistically significant differences of skin lesion as well as mucosal lesion of pemphigus after 6 weeks of therapy between of two groups $(\mathrm{P}<0.05)$. The most common adverse effects were increased body weight $(40 \%)$, increased appetite $(40 \%)$, and puffy face $(40 \%)$ in dexamethasone group. In prednisolone group, these side effects were $60 \%$ of the subjects. Other side effects in dexamethasone group were hyperglycemia (33.33\%), hypertension (26.66\%), and sleep disturbance (13.33\%). In prednisolone group, other side effects were hyperglycemia(33.33\%), hypertension(40\%), gastritis (33.33\%), nausea, vomiting (13.33\%) in each, reactivation of tuberculosis, herpes zoster infection, sleep disturbance, and mood change were $6.66 \%$ in each group. Conclusion: In the light of the findings of the study, we conclude that each of the treatment of dexamethasone group and prednisolone group is individually effective and safe in the treatment of pemphigus vulgaris but adverse effects are less in parenteral dexamethasone group than oral prednisolone group. So parenteral dexamethasone can be used as an alternative drug in the treatment of pemphigus vulgaris.
\end{abstract}

Key words: Safety of parenteral dexamethasone, safety of prednisolone, treatment of pemphigus vulgaris.

\section{Introduction:}

Pemphigus vulgaris (PV) is the most common variant and it constitutes $80 \%$ of patients with pemphigus. ${ }^{1}$ About $0.8 \%$ of all dermatologic patients suffer from pemphigus. ${ }^{2}$ The prevalence of pemphigus vulgaris is about equal in men and women. The mean age of onset is fourth to sixth decades. ${ }^{3}$ There is strong genetic background to pemphigus vulgaris and there is also HLA association in pemphigus vulgaris. ${ }^{2}$ In about $50-70 \%$ of the cases the disease begins with oral lesion, which may precede the cutaneous lesions by several months. Cutaneous lesions can be localized or generalized and usually present primarily as flaccid

Address of correspondence: Dr. Mohammad Jamal Uddin, Assistant Professor, Department of Dermatology and Venereology, BSMMU, Dhaka, Bangladesh.
[BSMMU J 2013; 6 (1): 38-43] vesicles or bullae varying in size from less than $1 \mathrm{~cm}$ to several $\mathrm{cm}$. The scalp, sternum, genitalia, axillae and groin are frequent sites of involvement. The blisters rupture easily and produce painful raw denuded areas. ${ }^{4}$ The Nikolsky's sign is the absence of cohesion in the epidermis, so the upper layers of the epidermis may easily be removed by a twisting pressure with the fingertip, leaving a moist surface. The bulla spreading phenomena can be tested by pressure on an intact bulla, gently forcing the fluid to wander under the skin away from site. ${ }^{3}$ Pemphigus vulgaris is associated with high morbidity as well as significant mortality rate, before the advent of systemic corticosteroid therapy in 1950 s. The mortality rate was reported varies from $70 \%$ to $100 \%$ before systemic corticosteroid use. The use of corticosteroid dramatically reduced the death rate to a mean of 
$30 \%{ }^{5}$ The course of pemphigus vulgaris is almost chronic. Dexamethasone is a long acting, synthetic steroid and prednisolone is an intermediate acting synthetic corticosteroid. ${ }^{2}$ Today the risk of death in pemphigus from the side effect of oral prednisolone is greater than risk of death from the disease itself. Death from sepsis and other complications of therapy (Diabetes, hypertension, electrolyte imbalance) occurs in $5 \%$ to $10 \%$ of treated cases. Untreated disease is usually fatal. In India mortality of pemphigus vulgaris is $>90 \%$ if untreated. The prognosis has dramatically improved with the use of systemic corticosteroids and various immunosuppressive agents. ${ }^{6}$ However, efficacy and safety of prednisolone is established therapy to achieve a good control of PV but associated with several distressing side-effects. Several studies also carried out previously to determine the efficacy of dexamethasone and there is no doubt about the effectiveness. So, an endeavor had been made here to find out the adverse effects of dexamethasone, there by we use dexamethasone to control the pemphigus vulgaris in stead of prednisolone.

\section{Methods:}

An interventional study was carried out in the department of Dermatology and Venereology, Bangabandu Sheikh Mujib Medical University, Dhaka. The period of study was from January 2004 to June 2005. Total number of patient was thirty and among them, 15 patients were treated with injection dexamethasone(Group-A) and other 15 were treated with oral prednisolone(Group-B). Random sampling done and data were collected in pre-designed questionnaie. A detailed history was taken from the patient. In case of female, special attention was given regarding menstrual history and use of contraceptives. Clinical assessment was done at baseline, after every one week upto 6 weeks. Clinical assessment tools include number of skin lesion of pemphigus, number of mucous membrane lesion of pemphigus, positive Nikolsky's sign, presence of bulla spreading phenomena and other physical examination. Laboratory assessment was done at baseline and two weeks after therapy and at the end of six weeks.

Monitoring of adverse effect was done after 2 weeks, at the end of 4 weeks and after 8 weeks by query of symptoms of different system, physical examination and laboratory test. Information obtained from history, physical examination and laboratory investigation (Routine blood examination-Total count, Differential count, $\mathrm{Hb} \%$ and ESR, urine routine examination, blood sugar, blood urea, serum creatinine, liver function test, ECG, skin biopsy for histopathology \& direct immunofluorescence test) were recorded in patient data sheet.

Thirty patients were included in this study using random number table. 15 patients were treated with injection Dexamethasone(Group-A) and 15 patients with oral prednisolone(Group-B). First on admission we gave $5 \mathrm{mg}$ injection Dexamethasone 8 hourly intravenously. This dose was continued until cessation appearance of new bulla. Then the dose was reduced $5 \mathrm{mg} 12$ hourly. After gradual, improvement of patient's condition the dose was reduced to $5 \mathrm{mg}$ intravenously daily. After 6 weeks we assessed the patient's outcome. The initial dose of prednisolone was (equivalent to $15 \mathrm{mg}$ dexamethasone) $100 \mathrm{mg}$ daily in divided doses. It was continued until cessation of new bulla appeared. After that improvement, steroid doses were rapidly reduced by $20 \mathrm{mg} /$ week upto dose $60 \mathrm{mg} /$ week, then $10 \mathrm{mg} /$ week upto dose 40 $\mathrm{mg} /$ week, then $5 \mathrm{mg} /$ week upto $20 \mathrm{mg} /$ week, then reduction of $2.5 \mathrm{mg} /$ week and then gradually dose were tapered during the follow-up period. After six weeks, we assess the patient's condition.

All statistical analysis was done by SPSS 12 software package as mean \pm Standard deviation (SD). $95 \%$ confidence limit was taken as level of significance. Comparison between two groups were done by unpaired ' $t$ ' test and some qualitative data by 'Chi-square test. Comparison within group was done by paired 't' test. $\mathrm{P}<0.05$ was considered as a level of significance.

\section{Results:}

Thirty patients of pemphigus vulgaris were enrolled in this study and of them 15 were enrolled in the injection dexamethasone group $\mathrm{A}$ (odd random table number) and 15 in the oral prednisolone group B. Table I showed that all demographic, clinical parameter were almost identical in two groups $(\mathrm{P}>0.05)$. Variable are expressed as mean \pm SD. Sex expressed as ratio. Nikolsky's sign and bulla spreading phenomena expressed as number of patient. Table II showed statistically significant differences of skin lesion of pemphigus were observed after 6 
weeks between two groups $(\mathrm{P}<0.05)$. In table III, statistically significant differences of bulla spread phenomena of pemphigus were observed after 6 weeks between two groups $(\mathrm{P}<0.05)$ but regarding Nikolski’s sign, no statistically significant differences were observed between two groups. Table IV showed that the most common adverse effects were increased body weight $(40 \%)$, increased appetite $(40 \%)$, and puffy face $(40 \%)$ in Dexamethasone group. In prednisolone group these side effects were $60 \%$

\section{Table -I}

Baseline characteristics of two groups of study subjects.

\begin{tabular}{|c|c|c|c|}
\hline \multirow{2}{*}{ Characteristics } & Group $-\mathrm{A}$ & Group -B & \multirow{2}{*}{$P$ value } \\
\hline & $\begin{array}{l}\text { Dexamethasone } \\
\qquad(\mathrm{n}=15)\end{array}$ & $\begin{array}{l}\text { Prednisolone } \\
(\mathrm{n}=15)\end{array}$ & \\
\hline Age(yrs) & $41.60 \pm 13$. & $46.67 \pm 10.342$ & $>0.05$ \\
\hline \multicolumn{4}{|l|}{ Sex(male/Female) } \\
\hline Duration of & $4.53 \pm 1.846$ & $4.30 \pm 1.859$ & $>0.05$ \\
\hline Number of skin lesion. & $36.87 \pm 8.400$ & $36.27 \pm 8.980$ & $>0.05$ \\
\hline $\begin{array}{l}\text { Number of mucous } \\
\text { membrane lesion. }\end{array}$ & $3.40 \pm 2.613$ & $3.33 \pm 2.225$ & $>0.05$ \\
\hline Nikolsky sign & 15 & 15 & \\
\hline $\begin{array}{l}\text { Bulla spreading } \\
\text { phenomena }\end{array}$ & 15 & 15 & \\
\hline
\end{tabular}

Table-II

Out come of number of skin lesion and mucous membrane lesion of pemphigus after 6 weeks between two groups.

\begin{tabular}{llrr}
\hline Grouping & $\begin{array}{l}\text { No. of skin lesion of } \\
\text { pemphigus } \\
\text { mean } \pm \mathrm{SD}\end{array}$ & t v alue & Level of significance \\
\cline { 3 - 4 } & $5.27 \pm 1.624$ & -3.813 & \\
\hline Group -A & $7.73 \pm 1.907$ & Lalue \\
Group=B & $\begin{array}{l}\text { No. of mucous } \\
\text { membrane lesion of } \\
\text { pemphigus } \\
\text { mean } \pm \text { SD }\end{array}$ & t value & P value \\
Grouping & $1.00 \pm 0.926$ & & \\
Group -A & $1.87 \pm 1.246$ & -2.162 & $<0.05$ \\
Group=B & & & \\
\hline
\end{tabular}


Table-III

Outcome of Nikolski's sign and Bulla spread phenomena between Dexamethasone (Group-A) and prednisolone (Group-B) after 6 weeks.

\begin{tabular}{lccc}
\hline Study group & \multicolumn{2}{c}{ Nikolski's sign } & Chi-square value \\
\cline { 1 - 2 } & Positive & Negative & \\
Group A & 4 & 11 & $\begin{array}{l}1.292 \text { ( P value } \\
>0.05)\end{array}$ \\
Group B & 7 & 8 &
\end{tabular}

\begin{tabular}{lccc}
\hline Study group & \multicolumn{3}{c}{ Bulla spread Chi-square value } \\
\hline & phenomena & & \\
\cline { 1 - 2 } Group A & Positive & Negative & -9.130 (P value \\
Group B & 0 & 15 & $<0.05$ )
\end{tabular}

Table-IV

Distribution of study subjects by adverse effects of drugs.

\begin{tabular}{llc}
\hline Adverse effects & \multicolumn{2}{c}{ Group } \\
\cline { 2 - 3 } & $\begin{array}{c}\text { Group-A } \\
\text { Dexamethasone } \\
\text { therapy }\end{array}$ & $\begin{array}{c}\text { Group-B } \\
\text { Prednisolone } \\
\text { therapy }\end{array}$ \\
\hline Increased body weight & $6(40.00 \%)$ & $9(60.00 \%)$ \\
Increased appetite & $6(40.00 \%)$ & $9(60.00 \%)$ \\
Hyperglycemia & $5(33.33 \%)$ & $5(33.33 \%)$ \\
Hypertension & $4 .(26.66 \%)$ & $6(40.00 \%)$ \\
Puffy face & $6.40 .00 \%)$ & $9(60.00 \%)$ \\
Sleep disturbance & $2(13.33 \%)$ & $1(6.66 \%)$ \\
Nausea, vomiting & $0(0 \%)$ & $2(13.33 \%)$ \\
Gastritis & $0(0 \%)$ & $5(33.33 \%)$ \\
Infection(Herpes Zoster) & $0(0 \%)$ & $1(6.66 \%)$ \\
Reactivation of & & \\
Tuberculosis & $0(0 \%)$ & $1(6.66 \%)$ \\
Mood change & $0(0 \%)$ & $1(6.66 \%)$ \\
\hline
\end{tabular}

\section{Discussion:}

The age of the patients enrolled in the study group ranged from 20-69 years with mean age in dexamethasone group was $41.60 \pm 13.27$ years and prednisolone group was $46.67 \pm 10.34$ years. In study by GG Toth, the average age was 47.7 years. ${ }^{7}$ Statistically significant improvement was observed in dexamethasone group in all clinical param- eters i.e number of skin lesion of pemphigus, number of mucous membrane lesion of pemphigus and bulla spreading phenomena. But on Nikolsky's sign we did not found any significant difference between dexamethasone and prednisolone group after 6 weeks. This result were consistent with finding of other study. In their study, the dose of dexamethasone was higher, $200 \mathrm{mg}$ daily. In study by Amrinder et al, they include cyclophosphamide with dexamethasone in the treatment of pemphigus vulgaris. ${ }^{8}$ They found significant improvement with this therapy. Leela et al, used cyclophosphamide with dexamethasone in treatment of pemphigus vulgaris. They found complete remission in $82 \%$ of patient in their study. Their follow up period was one years. ${ }^{9}$ Harman et al, in their study, they used azathioprine and in some patient used methotrexate with dexamethasone. Their dexamethasone dose was also high. They found significant improvement in their study. ${ }^{10}$ In our study we could not do follow up histopathology and immunofluronce test. But in other study they found significance reduction of antibody titer in direct and indirect immunofluronce test. ${ }^{11,12}$ Statistically we found both parenteral dexamethasone and oral prednisolone significant in early management of pemphigus vulgaris. This result were consistent with the findings of other study. It appeared that parenteral dexamethasone and oral prednisolone had similar efficacy in the early management of pemphigus vulgaris.

The most common adverse effect from parenteral therapy were weight gain $(40 \%)$, increase appetite $(40 \%)$ and puffy face $(40 \%)$. Other side effects were hyperglycemia (33.33\%), hypertension $(26.66 \%)$, sleep disturbance $(13,33 \%)$. A clinical trial was carried out with 28 cases of PV, aged 25-70 years, in department of Dermatology and Venereology, All India Institute of Medical Sciences, New Delhi, India by Sethy et al. They treated the Group A patients with Dexamethasone-cycloposphamide pulse (DCP) with daily oral cyclophosphamide and Group B patients with Cyclophosphamide pulse (CP) with daily oral prednisolone. Patients in both groups experienced immediate and delayed side-effects. The main sideeffects observed with group A were weight gain, hyper- 
dyspepsia, headache, hiccups, hypertension,

(episodic), nail discoloration, amenorrhea and hair fall. This was comparable to the side-effects noted in other studies, which included flushing (53.4\%), hiccups (1-6.1\%), dysgeusea (13\%), cushingoid features $(4 \%)$, diffuse hair loss $(29 \%)$, weight gain (11\%), candidial ( $8-100 \%$ in one study) and pyogenic infection $(3-100 \%$ in one study), generalized weakness (2.7\%), arthralgia $(33.3 \%$ ), hyperglycemia (none in one study to $18 \%$ ), amenorrhea $(2.7 \%)$, hypertension (none in one study to $3-11 \%)$, bradycardia $(58 \%)$ and steroid psychosis. In the $\mathrm{B}$ group, the major adverse events were nausea and vomiting, which were controlled with antiemetics, generalized weakness, secondary amenorrhea, diffuse hair fall and anemia. There were many side-effects attributable to concomitant daily prednisolone administration in this group, including reduced visual acuity due to posterior subcapsular cataract, hyperglycemia, weight gain, dyspnea due to weight gain, moon facies, hypertension and leucocytosis $(100 \%)$. No patient experienced hematuria (due to concomitant MESNA administration in all cases) or leucopenia. In other studies, patients on $\mathrm{CP}$ developed nausea and vomiting (44.4-100\%), leucopenia ( $22.2 \%$ ) and microscopic hematuria $(0-11.53 \%)$, which cleared with the coadministration of MESNA, amenorrhea (11.5-25\%), weight gain $(38.5 \%)$ and cataract $(7.7 \%)$ (due to the coadministration of daily prednisolone). On comparing the two groups, in Group A, dysgeusea, hiccups, palpitation, nail discoloration, bone pain and UTI were more common while in Group B, nausea, flushing, menstrual irregularity, secondary amenorrhea, dyspnea due to weight gain, moon facies and steroid withdrawal symptoms were more common. Steroid-associated side-effects were more in Group B, chiefly due to daily prednisolone. ${ }^{6}$

In study by Toth, they found diabetes is common side effect. They also found minor side effect like temporary facial flushing, sleep disturbance and mood change. ${ }^{7}$ In prednisolone group common side effects were increased body weight $(60 \%)$, increased appetite $(60 \%)$, and puffy mood change $(6.66 \%)$. One study reports that they found gastritis, hyperglycemia, hypertension, increased body weight, mood change and altered calcium/phosphate metabolism in prednisolone treated patient. ${ }^{8}$ It appeared that parenteral dexamethasone and oral prednisolone had similar efficacy but dexamethasone group had less adverse effects than prednisolone group in the early management of pemphigus vulgaris.

\section{Conclusion:}

In the light of the findings of the study, we conclude that each of the treatment of dexamethasone group and prednisolone group is individually effective and safe in the treatment of pemphigus vulgaris but adverse effects are less in parenteral dexamethasone group than oral prednisolone group. So parenteral dexamethasone can be used as an alternative drug in the treatment of pemphigus vulgaris. A study with larger sample size with long duration follow up of all cases is recommended to prove the safety of dexamethasone in early management of pemphigus vulgaris.

\section{References:}

1. Crispian S, Stephen J, Challacombe, Pemphigus vulgaris: update on etiopathogenesis, oral manifestration and management. Crit Rev Oral Biol Med, 2002;13(5):397-408.

2. Herbst A, Bystryn JC. Pattern of remission in pemphigus vulgaris. J am Acad Dermatol 2000;42:422-27.

3. Stanley JR. Autoimmune blistering dermatoses. Wolff $\mathrm{K}$, Goldsmith LA, Katz SI, Gilchrest BA, Paller AS and Leffell DJ. Fitzpatrick's Dermatology in General medicine. 6th Edition, New York: The McGraw- Hill Companies; 2008.558-67.

4. Stephen E. Systemic corticosteroid. Wolverton. Comprehensive Dermatologic Drug Therapy, $2^{\text {nd }}$ Edition: W.B Saunders Company; 2001. 109-146.

5. Victoria PW. Systemic corticosteroid. Fitzpatrick's dermatology in general medicine, $6^{\text {th }}$ Edition, New York: Mc Graw Hill Companies Publisher; 2008. 2381-2388

6. Sethy PK, Khandpur S, Sharma VK. Randomized open comparative trial of dexamethasone-cyclophosphamide pulse and daily oral cyclophosphamide versus cyclophosphamide pulse and daily oral prednisolone in pemphigus vulgaris. Indian J Dermatol Venereol Leprol 2009;75:476-82.

7. Toth GG, Van de, Meer JB, Jonkman MF. Dexamethasone pulse therapy in pemphigus. J Eur Acad Dermatol Venereol. 2002;16(6):562-63. 
8. Amrinder J, Kanwar, Sukhjot K, Gurvinder P T. Long term efficacy of Dexamethasone-cyclophosphamide pulse Therapy in Pemphigus. Dermatology 2006;204:228-31.

9. Leela E, Kailash C, Bhol and Ahmed A.R. Analysis of Current data on the use of intravenous immunoglobulins in management of Pemphigus vulgaris. J Am Acad Dermatol 2009;43:1049-57.

10. Carson P, Hemeed A, Razzaque AA. Influence of treatment on the clinical course of pemphigus vulgaris. J Am Acad Dermatol 1996:34:645-52.

11. Harman S, Albert, Black MM. Guidelines for management of Pemphigus vulgaris. British Journal of Dermatology 2003;149:926-37.

12. Bystryn J, Steinman N. The adjuvant therapy of pemphigus ; an update.Arch Dermatol 1996;132:203-12. 